\title{
Design and Optimization of a Fast Switching Hydraulic Step-Down Converter for Position and Speed Control
}

\author{
Marcos P. Nostrani ${ }^{1}$, Alessio Galloni ${ }^{2}$, Henrique Raduenz ${ }^{1}$, Victor J. De Negri ${ }^{1}$ \\ ${ }^{1}$ Mechanical Engineering Department, Federal University of Santa Catarina, Florianópolis, SC/Brazil \\ E-mail: marcos.nostrani@gmail.com, alessio.galloni@hotmail.com, henrique@laship.ufsc.br, \\ victor.de.negri@ufsc.br \\ ${ }^{2}$ Università degle studi di Modena e Reggio Emilia, Modena, Italy
}

\begin{abstract}
This paper presents a design process of a hydraulic step-down switching converter considering the load losses in the inertance tube and switched valve. A steady state analysis for the switching converter as well as nonlinear dynamic simulation results of a digital hydraulic position and speed control system are presented. The results using the steady state and dynamic models are validated by experimental results obtained using a hydraulic test bench able to apply different loads to the system. The results show that steady-state model provides a very good approach to perform the preliminary design of hydraulic switching converters. The impact of tube parameters in the system efficiency is also discussed.
\end{abstract}

Keywords: Digital hydraulics, Hydraulic step-down converter, PWM switched valve.

\section{Introduction}

New hydraulic systems and components have been developed in the last decades, most of them resulting from the integration of electronic devices and improvement of manufacturing. However, hydraulic systems are known by their low efficiency, usually below $50 \%$ [1] caused by the extensive use of valves that throttle the flow to control pressure and flow rate, generating heat. Despite of that, hydraulic systems are extremely used in many fields due to the low weight power ratio and great reliability [2].

In order to improve the hydraulic systems efficiency, new technologies have been investigated. One approach is either the velocity and position control using variable displacements pumps and motors [3] or fixed and variable pumps driven by variable speed electrical motors [4] [5]. Moreover, another technology in development is the digital hydraulics [2] [6] [7] [8].

Digital hydraulics emerges as a technique to avoid the resistive pressure and flow rate control using mainly on/off valves. This new technology has two major derivations. The first denominated Parallel Connection connects in parallel several hydraulic components in order to provide discrete output values [9]. The second is known as Fast Switching Hydraulics (FSH). In these systems, the input signals usually use the pulse-width modulation technique (PWM) where the system output is set by the input duty cycle. For FSH systems, normally an inductive element is used for implementing fluid inertia. The most used element (for that purpose) is a hydraulic tube with high length and small diameter called Inertance Tube. The characteristic behaviour of these systems is determined by the valve-tube configuration. If the tube is placed before the valve, the system is called pressure booster or step-up converter. On the opposite case, the system is called flow booster or stepdown converter [6] [10] [11].

The FSH systems were initially studied by Brown in the 1980s [12] [13] where high efficiency is expected, considering that flow and pressure control are not dissipative. However, as discussed in [1] and [14] , the valve and inertance tube introduce load losses that can reduce the efficiency considerably. Therefore, the correct choice of the parameters of the system such as diameter and length of the tube can significantly influence its performance.

In this paper, the design of a digital fast switching hydraulic step-down converter for position and speed control is presented. Experimental results obtained using a test bench are presented. Furthermore, a mathematical steady-state model and a nonlinear model of the entire system are presented-and the simulation results compared.

\section{Hydraulic Step-Down Converter}

The fundamental circuit of a hydraulic step-down converter is shown in fig. 1. This system is basically composed by a switching on/off valve and an inertance tube. The output pressure can be modulated from the low supply pressure to the high supply, working as a pressure regulator.

The working principle of a hydraulic step-down converter is based in the acceleration and deceleration of the fluid mass inside the inertance tube by fast switching the valve. According to Figure 1, when the valve connects ports $\mathrm{P}$ to A, keeping $\mathrm{T}$ closed, the internal pressure $\left(p_{\text {Ain }}\right)$ increases to 
the high supply pressure $\left(p_{H S}\right)$. It causes the acceleration of the fluid inside the inertance tube. When the valve switches to the other position, linking port $\mathrm{T}$ to $\mathrm{A}$ and closing $\mathrm{P}$, the fluid momentum inside the tube makes the internal pressure to fall below the low supply pressure $\left(p_{L S}\right)$, suctioning fluid from the low pressure supply line [14]. This system arrangement needs a low supply pressure different than zero in order to avoid cavitation. The output load pressure $\left(p_{L}\right)$ value can be varied by the PWM duty cycle $(\kappa)$, that is the portion of time in which the valve remains opened to the high supply pressure during a certain switching period.

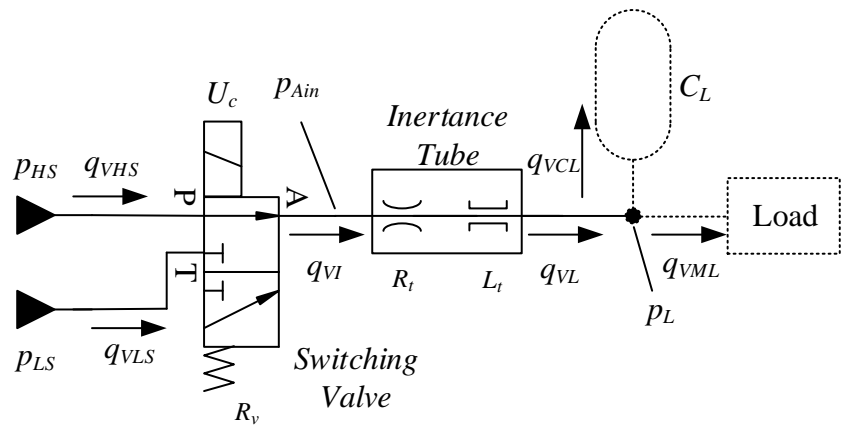

Figure 1 - Step-Down fundamental hydraulic circuit.

Figure 2 shows the PWM signal applied to the valve as well as the average load pressure.

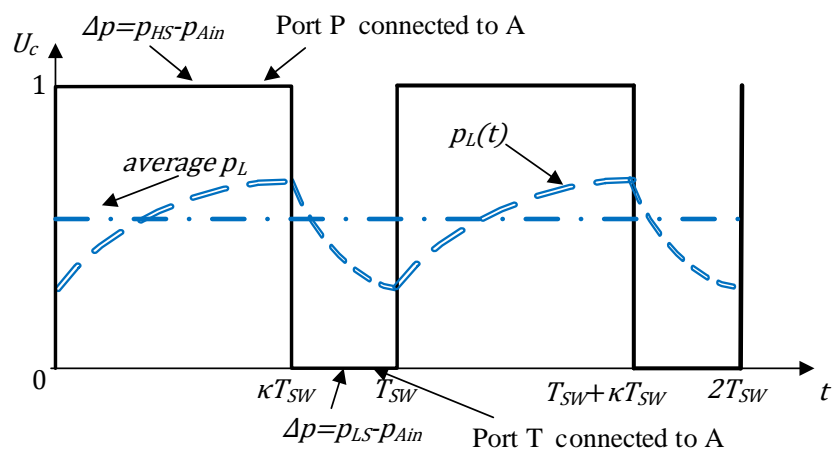

Figure 2 - System response representation.

In order to predict the real system behaviour, a mathematical steady-state was proposed in [14] and a nonlinear dynamic model presented in [15]. These models were used to design a position and speed control system aiming to achieve the higher efficiency as possible without compromising the system dynamics. The models have been developed considering the scheme shown in fig. 3 .

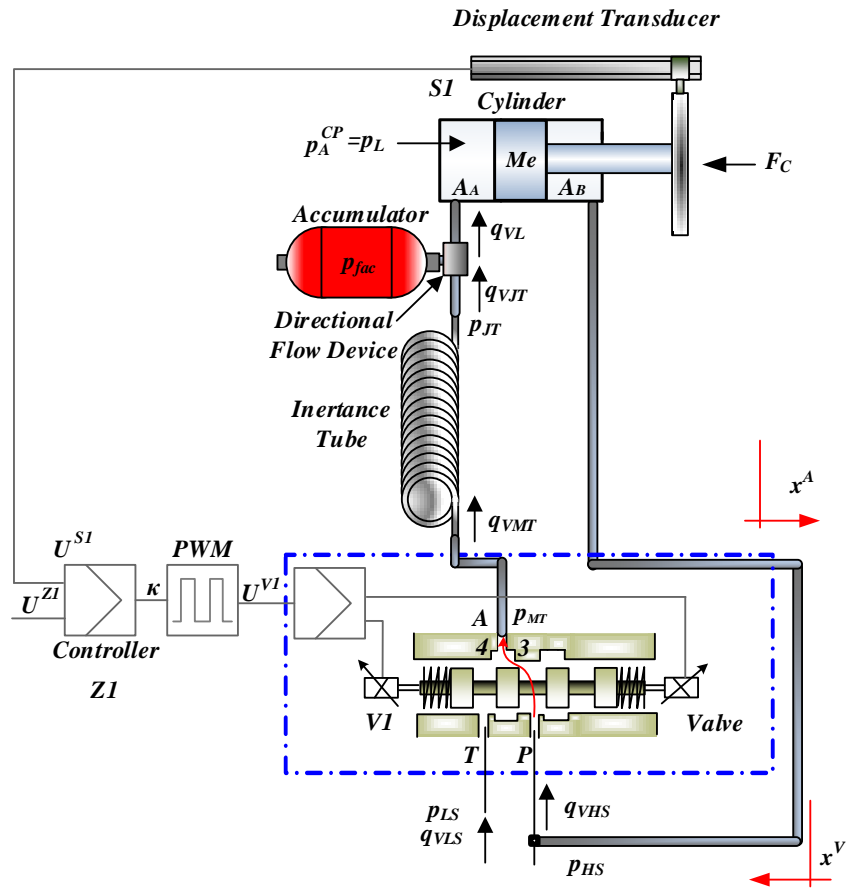

Figure 3 - Fast switching hydraulic step-down converter scheme (Adapted from [16]).

\section{Dimensioning of the Step-Down Converter}

\subsection{Steady-State Model}

A model describing the steady-state behavior of a hydraulic step-down converter was proposed in [14]. Based on that, the average output load pressure depends on the tube and valve resistances $\left(R_{e q}\right)$, the load flow rate $\left(q_{V L}\right)$, the supply pressures $\left(p_{H S}\right.$ and $\left.p_{L S}\right)$ and the PWM duty cycle $(\kappa)$ and can be calculated by:

$$
p_{L}=\left(p_{H S}-p_{L S}\right) \kappa+p_{L S}-q_{V L} R_{e q} .
$$

The step down system can modulate the load pressure from the low supply pressure $\left(p_{L S}\right)$ to the high supply pressure $\left(p_{H S}\right)$. However, when the required flow rate is different than zero, the load pressure is reduced by the load losses inside the inertance tube and valve.

The system efficiency can be evaluated dividing the power consumed by the power supplied by [14]:

$$
\eta=\frac{q_{V L}\left[p_{H S} \kappa+p_{L S}(1-\kappa)\right]-q_{V L}{ }^{2} R_{e q}}{\frac{\left(p_{H S}-p_{L S}\right)^{2} \psi}{R_{e q}}+q_{V L}\left[p_{H S} \kappa+p_{L S}(1+\kappa)\right]},
$$

where,

$$
\psi=\kappa(1-\kappa)-\frac{\tau\left(1-e^{-T_{s w}(1-\kappa) / \tau}\right)\left(1-e^{-T_{s w}{ }^{K} / \tau}\right)}{\left(1-e^{-T_{s w} / \tau}\right) T_{s w}} .
$$

The system efficiency depends on the switching period $\left(T_{S W}\right)$ and also the time constant $(\tau)$, besides the other 
system parameters mentioned before. The time constant is a function of the tube inductance and the equivalent system resistance $\left(\tau=L_{t} / R_{e q}\right)$, where the equivalent resistance is the sum of the valve $\left(R_{v}\right)$ and tube $\left(R_{t}\right)$ resistances. The tube inductance and resistance can be determined, respectively, by [17] [18]:

$$
L_{t}=\frac{4 \rho l_{t}}{\pi d_{t}^{2}}
$$

and

$$
R_{t}=\frac{128 \rho l_{t} \nu}{\pi d_{t}^{4}}
$$

The variation of the tube parameters (length and diameter) affects the time constant and, consequently, the system efficiency.

To have an initial estimative of tube length value, ref.[14] presents an equation for the optimum tube length for maximizing the efficiency without taking into account the valve resistance, that is:

$l_{t}=\frac{-f_{1} \psi+\sqrt{\left(f_{1} \psi\right)^{2}+f_{2}}}{f_{3}} \pi d_{t}^{4}$,

where.

$$
\begin{aligned}
& f_{1}=2 q_{V L}{ }^{2}\left(p_{H S}-p_{L S}\right)^{2}, \\
& f_{2}=4 q_{V L}{ }^{4}\left(p_{H S}-p_{L S}\right)^{2}\left[\left(p_{H S} \kappa+p_{L S}\right)^{2}-p_{L S}{ }^{2} \kappa^{2}\right], \text { and } \\
& f_{3}=256 q_{V L}{ }^{3} \rho v\left[p_{H S} \kappa+p_{L S}(1+\kappa)\right] .
\end{aligned}
$$

In the next section, the eq. (2) to (6) are used to select the tube aiming to achieve the highest efficiency.

\subsection{System Design}

The system analyzed is a wind turbine pitch angle $(\beta)$ positioning control prototype installed in the Laboratory of Hydraulic and Pneumatic Systems - Laship at Federal University of Santa Catarina - UFSC (fig. 4). The system comprises two double acting cylinders (Bosch Rexroth CDT3MT4/80/56/500/Z/1X/B11HFDTWW), two proportional reducing valves (Bosch Rexroth DREBE6X1X/175MG24K31A1M), a proportional directional valve (Parker D1FPE50MA9NB01) seven pressure transmitters (HBM P15RVA1, P2VA1 and Zürich PSI-420), tree flow transmitters (Webtec CT 60 and CT150) and an incremental encoder (Veerder Root). The two pressure reducing valves and one of the cylinders are used to emulate the load forces up to $30 \mathrm{kN}$.
The position control system was previously designed to operate on a classical configuration using a proportional directional valve [19]. Aiming to study the performance and efficiency of a step-down converter, the system has changed to the configuration shown in fig. 4 and fig. 5.

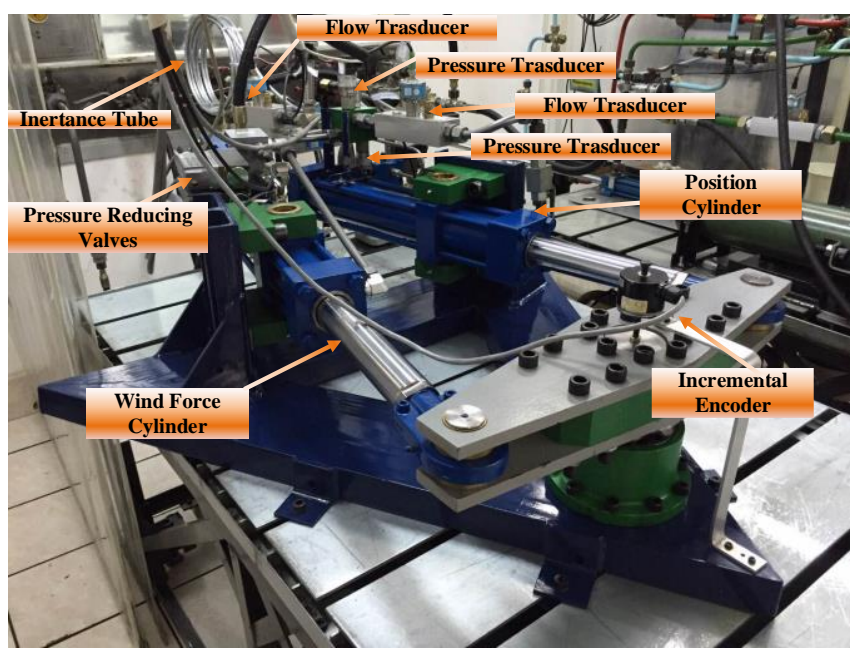

Figure 4 - Test rig: General view [15].

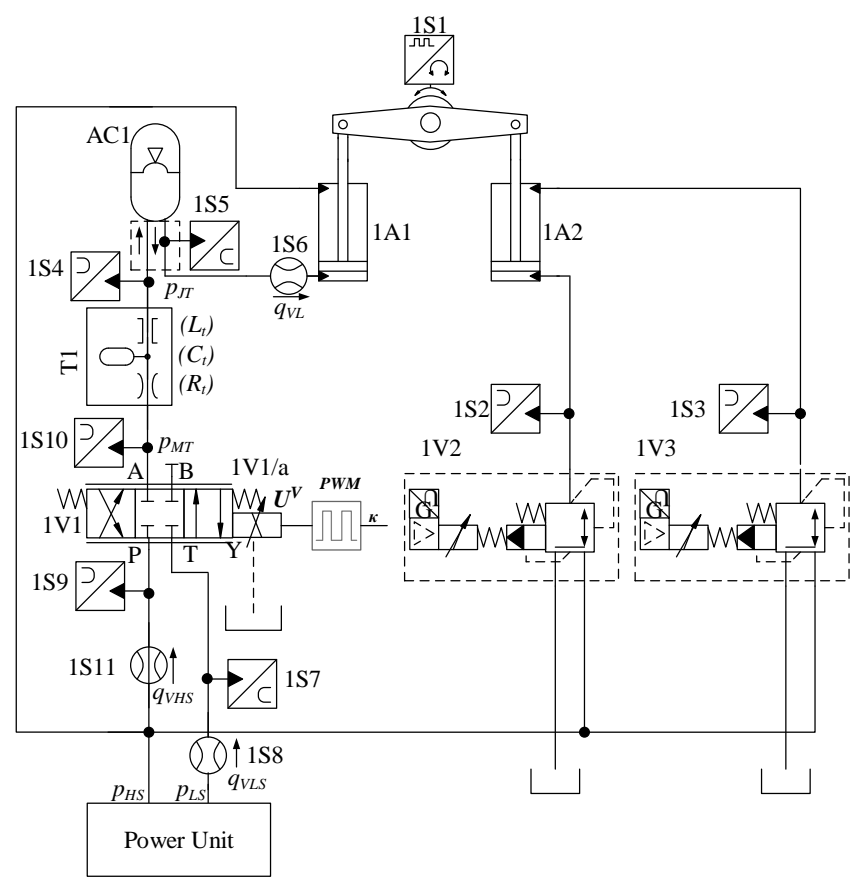

Figure 5 - Test rig: Hydraulic circuit diagram [15].

As discussed in [20] and [21], the required response of a closed loop positioning system can be described by a generic second order time step response. Therefore, assuming a critically damped behavior, the required settling time $\left(t_{s}\right)$ can be related to the system natural frequency $\left(\omega_{n}\right)$ by:

$$
\omega_{n}=\frac{6}{t_{s}}
$$

and the maximum velocity occurring at the step response is:

$$
v_{\max }=0.37 x_{R P} \omega_{n}
$$


being $x_{R P}$ the steady-state displacement.

Consequently, the corresponding maximum flow rate to the cylinder chamber $\mathrm{A}$ is given by:

$$
q_{V \max }=v_{\max } A_{A},
$$

where $A_{A}$ is the area of chamber A.

The maximum pitch angle in a wind turbine is around $25^{\circ}$ [22], for this reason an arbitrary angle of $8^{\circ}$ was chosen as the step magnitude during the tests. Considering the test bench assembly (see fig. 4), this angle corresponds to a cylinder displacement of $41.6 \mathrm{~mm}$. Assuming a desired settling time of $2 \mathrm{~s}$, the maximum flow rate to the cylinder and, consequently, through the inertance tube, is $2 \times 10^{-4}$ $\mathrm{m}^{3} / \mathrm{s}$ for a cylinder area of $50.26 \times 10^{-4} \mathrm{~m}^{2}$.

As mentioned before, switching period, tube length and diameter are the main parameters that must be defined to design an efficient step-down system. The system parameters are listed in Table 1, where the switching frequency was set to $32 \mathrm{~Hz}$ taking into account the capability of the proportional valve to fully switch with duty cycles between 10 and $90 \%$. The valve time response is 3.5 ms.

Equations (1) to (6) were implemented in Matlab in order to analyze the influence of the tube length and diameter in the system efficiency. Figure 6 shows the results for a duty cycle of $50 \%$, in which the influence of the parameters in the system performance is more significant [14].

Table 1-System parameters.

\begin{tabular}{|c|c|}
\hline Parameter & Value \\
\hline Effective Bulk modulus $-\beta_{e}$ & $1.6 \times 10^{9} \mathrm{~Pa}$ \\
\hline High supply pressure $-p_{H S}$ & $12 \mathrm{MPa}$ \\
\hline Kinematic viscosity $-v$ & $32 \times 10^{-6} \mathrm{~m}^{2} / \mathrm{s}$ \\
\hline Low supply pressure $-p_{L S}$ & $1 \mathrm{MPa}$ \\
\hline Load average flow rate $-q_{V L}$ & $2 \times 10^{-4} \mathrm{~m}^{3} / \mathrm{s}$, \\
\hline Switching period $-T_{S w}$ & $31.25 \mathrm{~ms}$ \\
\hline Density $-\rho$ & $870 \mathrm{~kg} / \mathrm{m}^{3}$ \\
\hline Valve resistance $-R_{v}$ & $3.88 \times 10^{9} \mathrm{~Pa} . \mathrm{s} / \mathrm{m}^{3}$ \\
\hline
\end{tabular}

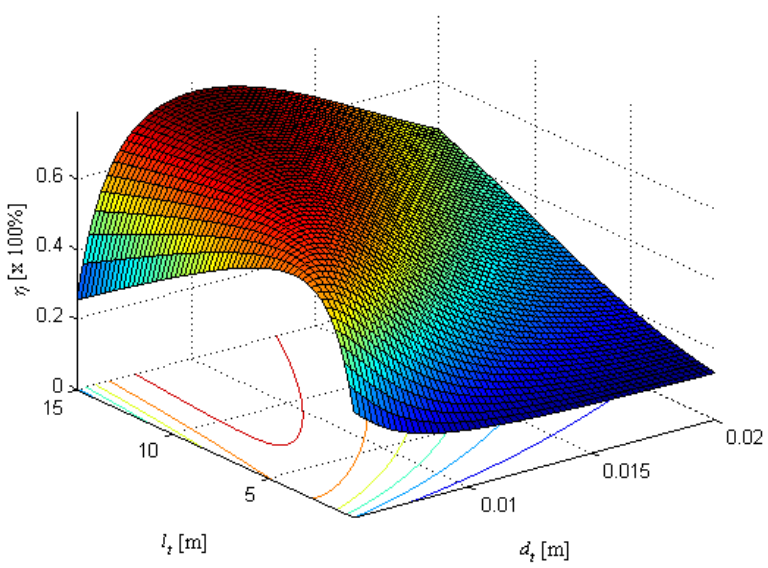

Figure 6- Efficiency for different tube length and diameters.
The results show that the system efficiency has a significant variation with different tube lengths and diameters. An initial estimative of the tube length and efficiency as function of the tube diameter can be obtained using eq. (6) and eq. (2), respectively, resulting on the curves shown in Figure 7.

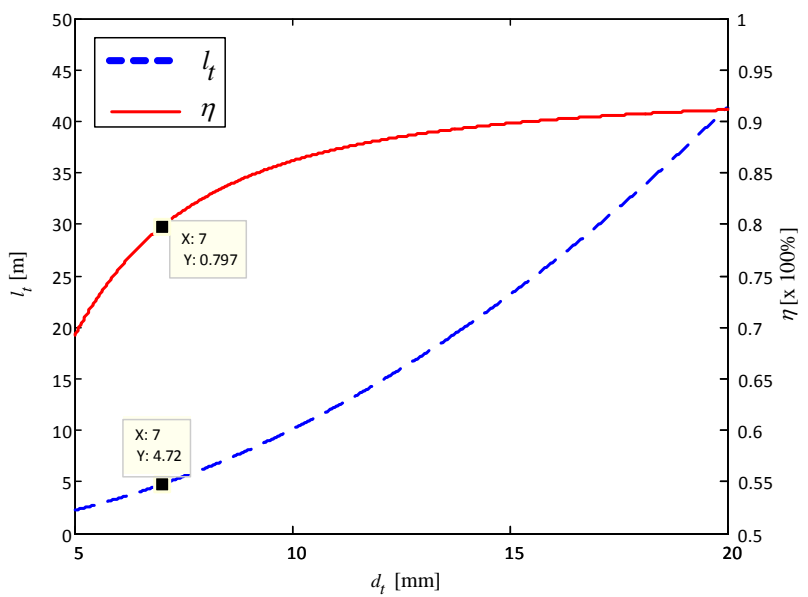

Figure 7- Tube length and efficiency versus diameter.

According to this figure, as the inner diameter of the tube increases, the length must be increased as well to result in the maximum efficiency, which also increases along with the diameter. Observing fig. 7 , in this study a $7 \mathrm{~mm}$ tube diameter was chosen, resulting on a tube length equal to $4.72 \mathrm{~m}$ and a system efficiency of $79.7 \%$.

However, as discussed in [14], the valve induces significant losses in the system and, therefore, its effect must be taken into account to calculate the final tube length. Fixing the tube diameter in $7 \mathrm{~mm}$, the lengths resulting on maximum efficiencies can be calculated using eq. (2). These results are shown in fig. 8 where considering the valve resistance shown in Table 1, the resulting tube length is $7.76 \mathrm{~m}$ with system efficiency of $69.11 \%$. For the experimental system, a commercial tube of $6 \mathrm{~m}$ length and $7 \mathrm{~mm}$ diameter was chosen, resulting on an efficiency of $68.22 \%$ (eq. (2)).

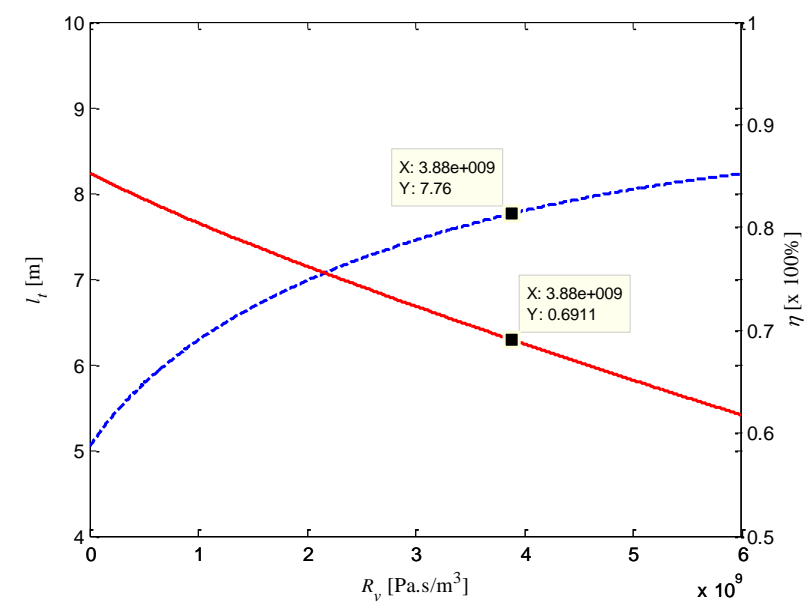

Figure 8-System efficiency with the valve resistance. 


\section{Dynamic Analysis}

\subsection{Nonlinear model}

In order to predict the system dynamics using switched hydraulics, a nonlinear mathematical model was implemented in Matlab/Simulink and validated experimentally. The model has been developed considering the components shown in fig. 3 and the parameters presented in Table 2.

The flow rate $q_{V M T}$ through the switching valve can be expressed by:

For $x^{V} \geq 0\left(U^{V 1}=10 \mathrm{~V}\right)$ :

$$
\begin{gathered}
q_{V M T}=\left(K_{v_{A}} \cdot \frac{U^{V 1}}{U_{n}}+K_{v i n}\right) \cdot \sqrt{p_{H S}-p_{M T}} \\
+K_{v i n} \cdot \sqrt{p_{L S}-p_{M T}}
\end{gathered}
$$

For $x^{V}<0\left(U^{V 1}=-10 \mathrm{~V}\right)$ :

$$
\begin{gathered}
q_{V M T}=\left(K_{v_{A} \cdot} \frac{\left|U^{V 1}\right|}{U_{n}}+K_{v i n}\right) \cdot \sqrt{p_{L S}-p_{M T}} \\
-K_{v i n} \cdot \sqrt{p_{H S}-p_{M T}} .
\end{gathered}
$$

where $U^{V 1}$ is the control signal, $U_{n}$ the nominal valve signal, $K_{v_{A}}$ the flow coefficient, $K_{v i n}$ the leakage coefficient and $p_{M T}$ the inlet tube pressure.

The accumulator is assembled in a flow direction device and its internal pressure, that it is equal to the tube downstream pressure, is described by:

$$
\frac{d p_{f a c}}{d t}=\frac{q_{V J T}-c_{d} A_{D C} \sqrt{\frac{2}{\rho}\left(p_{f a c}-p_{A}^{C P}\right)}}{\frac{1}{\gamma} \frac{\left(V_{0}-V_{f a c}\right)^{\gamma+1}}{V_{o}^{\gamma}} \frac{1}{p_{o}}+\frac{V_{f a c}}{\beta_{e}}} .
$$

where $q_{V J T}$ is the inlet flow rate to the accumulator, $V_{0}$ the initial volume, $V_{f a c}$ the fluid volume, $p_{o}$ the accumulator initial pressure, $p_{L}$ the load pressure, $c_{d}$ the discharge coefficient, $A_{D C}$ the flow passage area and $\gamma$ the specific heat ratio of the gas.

The hydraulic actuator was modelled according the continuity equation and Newton's Second Law, resulting on:

$$
q_{V L}=A_{A} \frac{d x^{A}}{d t}+\frac{V_{A}+x^{A} A_{A}}{\beta_{e}} \frac{d p_{A}^{C P}}{d t},
$$

and

$$
\left(p_{A}^{C P} \cdot A_{A}\right)-\left(p_{H S} \cdot A_{B}\right)=M_{e} \frac{d^{2} x^{A}}{d t^{2}}+F_{a t}+F_{c},
$$

where $A_{A}$ is the chamber $\mathrm{A}$ area, $A_{B}$ the chamber $\mathrm{B}$ area, $p_{A}^{C P}$ the chamber A pressure, $F_{a t}$ the friction force, $F_{C}$ the load force, $V_{A o}$ the chamber $\mathrm{A}$ initial volume and the $V_{A}$ the chamber A volume. Friction force parameters used were based on [15], [22] and [23].

The inertance tube has been modelled according to the TLM (Transmission Line Method). More details can be found in [24], [25] and [26].

Table 2- System complementary parameters.

\begin{tabular}{|c|c|}
\hline Parameter & Value \\
\hline Effective Bulk modulus $-\beta_{e}$ & $1.6 \times 10^{9} \mathrm{~Pa}$ \\
\hline High supply pressure $-p_{H S}$ & $12 \mathrm{MPa}$ \\
\hline Kinematic viscosity $-v$ & $32 \times 10^{-6} \mathrm{~m}^{2} / \mathrm{s}$ \\
\hline Low supply pressure $-p_{L S}$ & $1 \mathrm{MPa}$ \\
\hline Load average flow rate $-q_{V L}$ & $2 \times 10^{-4} \mathrm{~m}^{3} / \mathrm{s}$, \\
\hline Switching period $-T_{S w}$ & $31.25 \mathrm{~ms}$ \\
\hline Leakage coefficient $-K_{v i n}$ & $1.4907 \times 10^{-9} \mathrm{~m}^{3} / \mathrm{s} . \mathrm{Pa}^{1 / 2}$ \\
\hline Flow coefficient $-K_{v_{A}}$ & $3.5635 \times 10^{-7} \mathrm{~m}^{3} / \mathrm{s} . \mathrm{Pa}^{1 / 2}$ \\
\hline Accumulator volume $-V_{0}$ & $0.350 \mathrm{~L}$ \\
\hline Accumulator pre-load $-p_{o}$ & $5 \mathrm{MPa}$ \\
\hline Discharge coefficient $-c_{d}$ & 0.7 \\
\hline Flow passage area $-A_{D C}$ & $3.4510^{-5} \mathrm{~m}^{2}$ \\
\hline Specific heat ratio $-\gamma$ & 1.4 \\
\hline Density $-\rho$ & $870 \mathrm{~kg} / \mathrm{m}^{3}$ \\
\hline Valve resistance $-R_{v}$ & $3.88 \times 10^{9} \mathrm{~Pa} . \mathrm{s} / \mathrm{m}^{3}$ \\
\hline Equivalent mass $-M_{e}$ & $63.4 \mathrm{~kg}$ \\
\hline
\end{tabular}

\subsection{Simulation and Experimental Results}

Figure 9 and Figure 10 show the pitch angle and the load pressure, respectively, for a sequence of step inputs. The system load is $5000 \mathrm{~N}$ against the actuator movement, and the proportional and integral gains are 0.7 and 0.1 , respectively. The switched frequency used in the experiments is $32 \mathrm{~Hz}$.

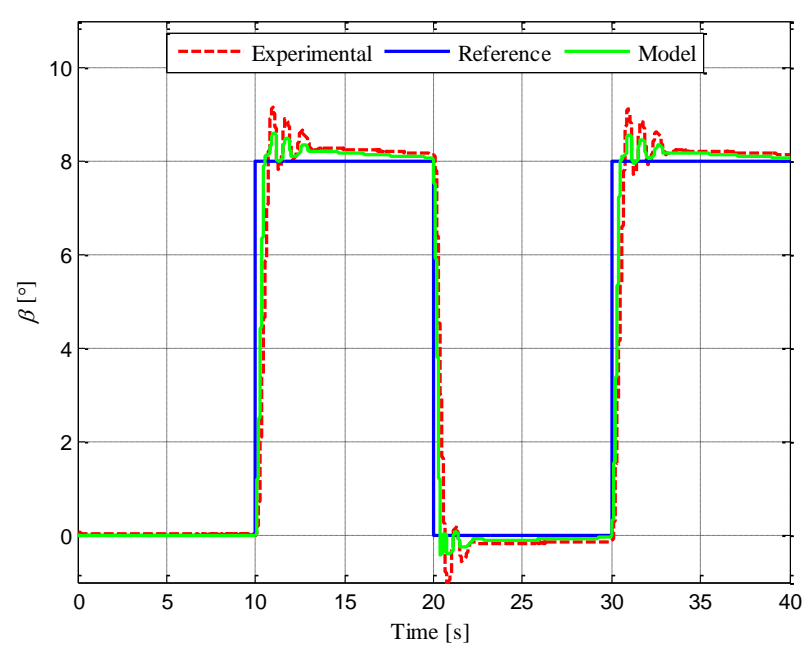

Figure 9 - Position control-Output Response. 


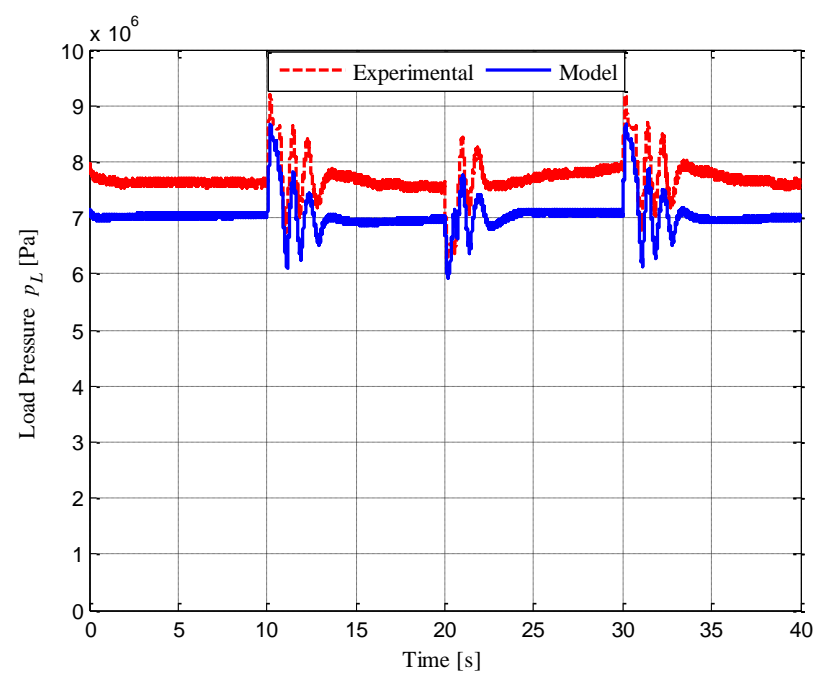

Figure 10 - Position control-Load pressure.

The results show that the model describes the real system with high accuracy, despite that the experimental load pressure is higher than the simulation results, due to the friction forces in the bearings that were not considered in the model.

The system response in open loop configuration was also analyzed by simulation. In this case, a PWM input voltage with duty cycle of $70 \%$ was applied to the valve and a constant load of $5000 \mathrm{~N}$ at the cylinder rod. Figure 11 shows the cylinder position in this open loop speed control configuration.

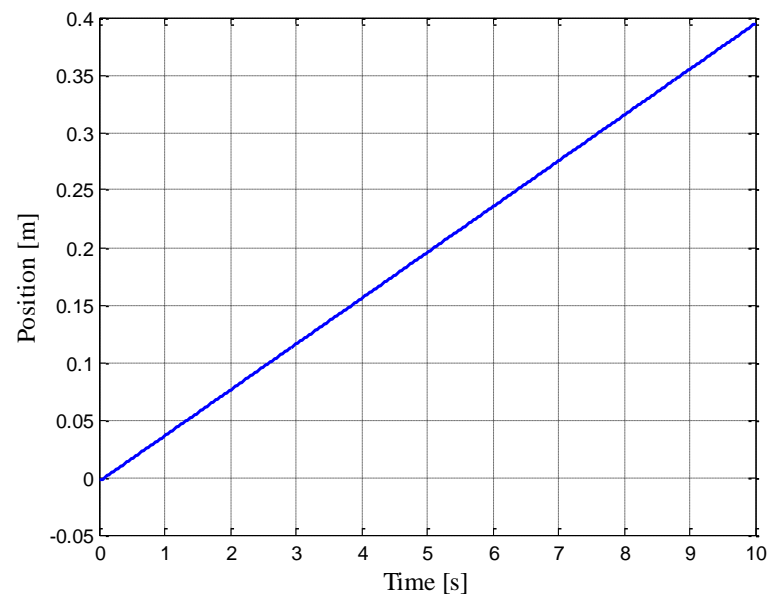

Figure 11 - Speed control-Cylinder Stroke.

Figure 12 and Figure 13 show the behavior of the load pressure and the load flow rate, respectively. The resulting velocity is $0.039 \mathrm{~m} / \mathrm{s}$ and the average load pressure and average flow rate are $7.42 \times 10^{6} \mathrm{~Pa}$ and $1.99 \times 10^{-4} \mathrm{~m}^{3} / \mathrm{s}$, respectively. The flow rate value is very close to those used for the system design.

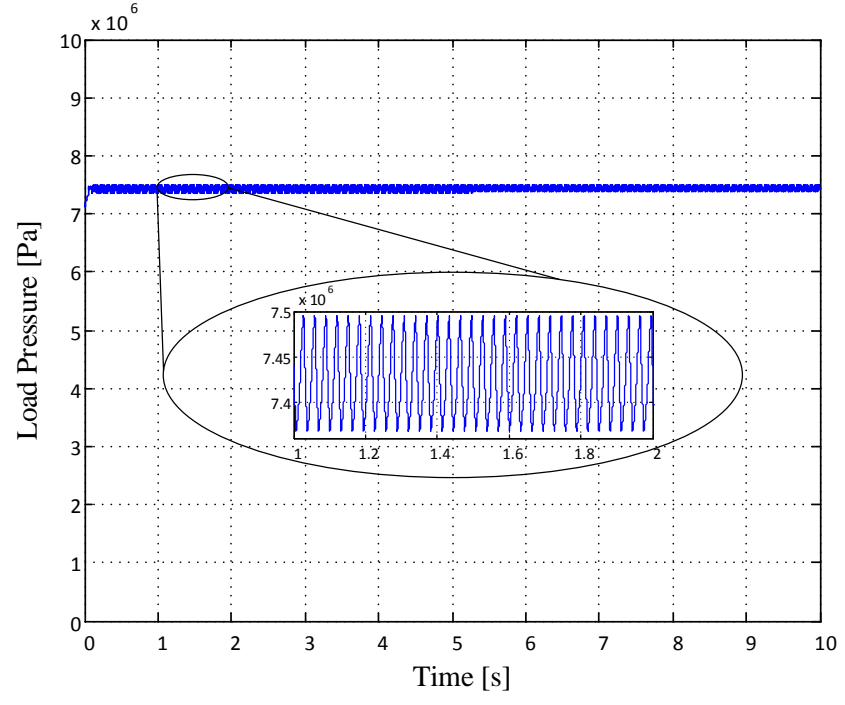

Figure 12 - Speed control-Load pressure.

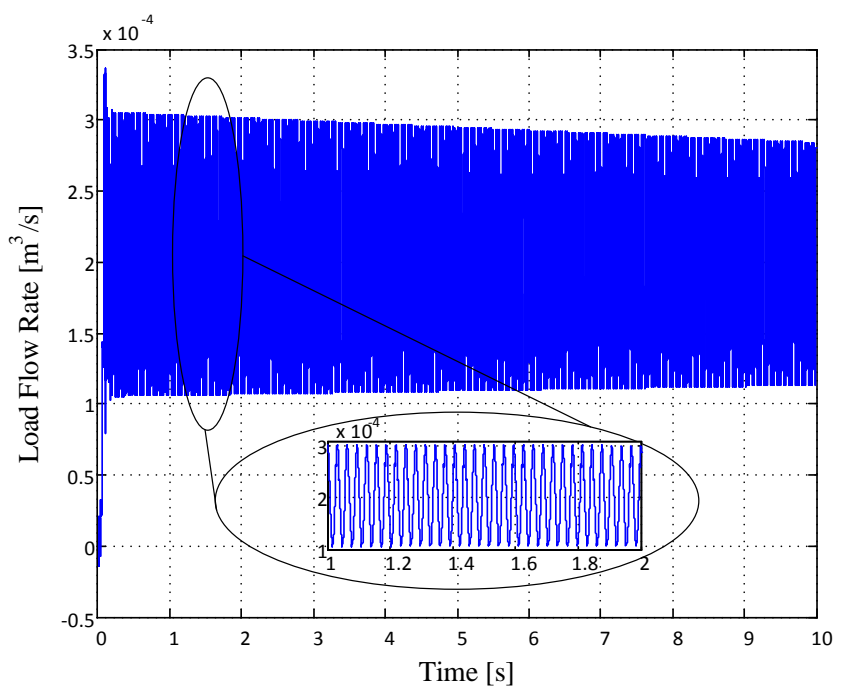

Figure 13 - Speed control - Load Flow rate.

\subsection{Efficiency Analysis}

In this section, the responses of the speed control system are compared with the results obtained using the steady state model presented in Section 3.1, aiming to verify the predicted performance using the chosen tube.

The energy associated to the cylinder chamber A can be evaluated according to:

$$
E_{A}(t)=\int_{0}^{t} p_{A}^{C P}(t) q_{V L}(t) d t
$$

and the energies at the high and low supply pressure ports calculated, respectively, by:

$$
E_{H P}(t)=\int_{0}^{t} p_{H S}(t) q_{V H S}(t) d t,
$$

and 


$$
E_{L P}(t)=\int_{0}^{t} p_{L S}(t) q_{V L S}(t) d t
$$

Therefore, based on simulation results using the nonlinear model, the system efficiency can be calculated by:

$$
\eta=\frac{E_{A}(t)}{E_{H P}(t)+E_{L P}(t)} .
$$

Figure 14 and Figure 15 show the load pressure and system efficiency, respectively, where the lines correspond to the results obtained using the steady-state model and the circle the operating point from the dynamic simulation. As mentioned in section 4.2, the system time response was analyzed with a duty cycle of $70 \%$ as input.

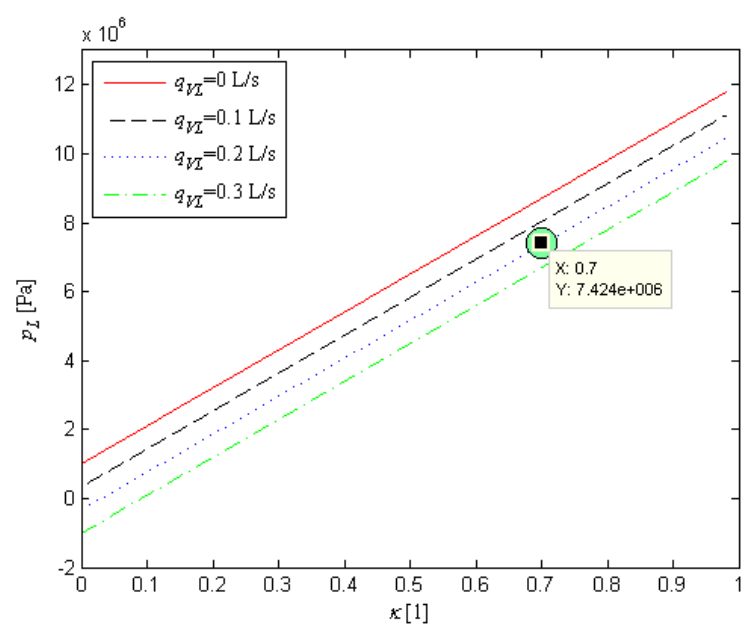

Figure 14 - Load pressure from the steady-state and dynamic models.

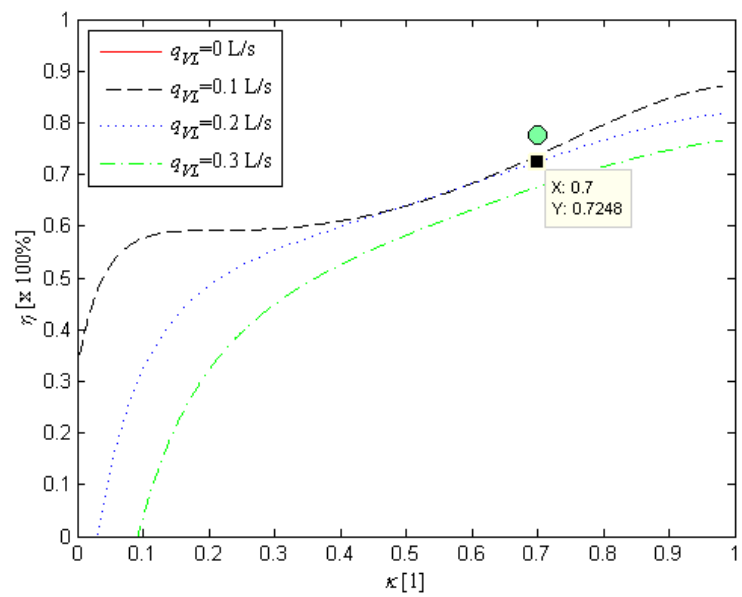

Figure 15 - Efficiency from for the steady-state and dynamic models.

As can be observed, the load pressure calculated by eq. (1) resulted on exactly the same average pressure obtained from dynamic simulation (fig. 12), that is $7.42 \times 10^{6} \mathrm{~Pa}$. The average flow rate resulting from the dynamic simulation is
$1.99 \times 10^{-4} \mathrm{~m}^{3} / \mathrm{s}$, while the flow rate used for the step-down system dimensioning is $2.00 \times 10^{-4} \mathrm{~m}^{3} / \mathrm{s}$.

For the system efficiency, both models result on efficiencies higher than $70 \%$ for a duty cycle of 0.7 . According to the steady state model, the efficiency is $72.48 \%$, higher than the estimated efficiency of $68.22 \%$ calculated for a duty cycle of 0.5 .

\section{Conclusions}

In this paper, the steady state equations modelling a hydraulic step-down converter were presented and used to determine the system parameters (tube length and diameter) in order to achieve the maximum efficiency.

The nonlinear dynamic equations of the position and speed control system were also introduced. Using the position control configuration (closed-loop system), the results showed that the mathematical model describes the system experimental behavior with good accuracy. As a result, the model could be used to validate the parameters obtained with the steady-state model.

Considering the system operating in open-loop configuration, the load pressure, flow rate, and efficiency predicted by the steady-state model matched very well the results obtained using dynamic simulation. Therefore, the steady-state model presented results on a very accurate design of a step-down converter. Moreover, the dynamic model can be used for system optimization and analysis of the dynamic response.

\section{Nomenclature}

\begin{tabular}{clc} 
Symbol & Denotation & Unit \\
\hline$\beta$ & Pitch angle & {$\left[{ }^{\circ}\right]$} \\
$\beta_{e}$ & Bulk modulus & {$[\mathrm{Pa}]$} \\
$\gamma$ & Specific heat ratio & {$[1]$} \\
$\kappa$ & Duty cycle & {$[1]$} \\
$v$ & Kinematic viscosity & {$\left[\mathrm{m}^{2} / \mathrm{s}\right]$} \\
$\eta$ & Hydraulic efficiency & {$[1]$} \\
$\rho$ & Density & {$\left[\mathrm{kg} / \mathrm{m}^{3}\right]$} \\
$A_{A}$ & Area of Chamber A & {$\left[\mathrm{m}^{2}\right]$} \\
$A_{D C}$ & Flow passage area & {$\left[\mathrm{m}^{2}\right]$} \\
$c_{d}$ & Discharge coefficient & {$[1]$} \\
$d_{t}$ & Tube diameter & {$[\mathrm{m}]$} \\
$E_{A}$ & Energy in cylinder line A & {$[\mathrm{J}]$} \\
$E_{H P}$ & High supply pressure energy & {$[\mathrm{J}]$} \\
$E_{L P}$ & Low supply pressure energy & {$[\mathrm{J}]$}
\end{tabular}




\begin{tabular}{clc}
$F_{a t}$ & Friction force & {$[\mathrm{N}]$} \\
$F_{C}$ & Load force & {$[\mathrm{N}]$} \\
$K_{v A}$ & Flow coefficient & {$\left[\mathrm{m}^{3} / \mathrm{s.} \mathrm{Pa}^{1 / 2}\right]$} \\
$K_{v i n}$ & Leakage coefficient & {$\left[\mathrm{m}^{3} / \mathrm{s.} \mathrm{Pa}^{1 / 2}\right]$} \\
$l_{t}$ & Tube length & {$[\mathrm{m}]$} \\
$M_{e}$ & Equivalent mass & {$[\mathrm{kg}]$} \\
$p_{A}^{C P}$ & Pressure in chamber A & {$[\mathrm{Pa}]$} \\
$p_{o}$ & Accumulator initial gas pressure & {$[\mathrm{Pa}]$} \\
$p_{g}$ & Accumulator gas pressure & {$[\mathrm{Pa}]$} \\
$p_{f a c}$ & Accumulator liquid pressure & {$[\mathrm{Pa}]$} \\
$p_{A i n}$ & Internal tube pressure & {$[\mathrm{Pa}]$} \\
$p_{J T}$ & Upstream tube pressure & {$[\mathrm{Pa}]$} \\
$p_{M T}$ & Downstream tube pressure & {$[\mathrm{Pa}]$} \\
$p_{L}$ & Load pressure & {$[\mathrm{Pa}]$} \\
$p_{H S}$ & High supply pressure & {$[\mathrm{Pa}]$} \\
$p_{L S}$ & Low supply pressure & {$[\mathrm{Pa}]$} \\
$q_{V J T}$ & Tube upstream flow rate & {$\left[\mathrm{m}^{3} / \mathrm{s}\right]$} \\
$q_{V L}$ & Load flow rate & {$\left[\mathrm{m}^{3} / \mathrm{s}\right]$} \\
$q_{V M T}$ & Tube downstream flow rate & {$\left[\mathrm{m}^{3} / \mathrm{s}\right]$} \\
$U_{c}$ & Control signal & {$[\mathrm{V}]$} \\
$U^{V 1}$ & Valve control signal & {$[\mathrm{V}]$} \\
$U_{n}$ & Nominal valve control signal & {$[\mathrm{V}]$} \\
$V_{A}$ & Volume of chamber A & {$\left[\mathrm{m}^{3}\right]$} \\
$V_{A o}$ & Initial volume of chamber A & {$\left[\mathrm{m}^{3}\right]$} \\
$V_{0}$ & Accumulator initial gas volume & {$\left[\mathrm{m}^{3}\right]$} \\
$V_{f a c}$ & Accumulator liquid volume & {$\left[\mathrm{m}^{3}\right]$} \\
$V_{g}$ & Accumulator gas volume & {$\left[\mathrm{m}^{3}\right]$} \\
\hline & & \\
& &
\end{tabular}

\section{References}

[1] DE NEGRI, V. J., WANG, P., JOHNSTON, D. N., PLUMMER, A., 2014. Behavioural prediction of hydraulic step-up switching converters. International Journal of Fluid Power. Vol 15, No. 1, pp. 1-9.

[2] LINJAMA, M., VILENIUS, M., 2005. EnergyEfficient Motion Control of a Digital Hydraulic Joint Actuator. Proceeding of the 6ht JFPS International Symposium on Fluid Power. Tsukuba, November 710.

[3] EGGERS, B., RAHMFELD, R., IVANTYSYNOVA, M., 2005. An energetic comparison between valveless and valve controlled active vibration damping for off-road vehicles. Proceedings of the $6^{\text {th }}$
JFPS International Symposium on Fluid Power. Tsukuba.

[4] WILlKOMM, J., WANLER, M. \& WEBER., J., 2014. Process-adapted control to maximize dynamics of displacement-variable pumps. Symposium on Fluid Power \& Motion Control. Bath, United Kingdom. pp. 10-12.

[5] TEIXEIRA, P. L., VIANNA, W., PENTEADO, R. D., KRUS, P. \& DE NEGRI., V. J., 2015. Pressure Modeling and Analysis of a Synchronized Hydraulic Press Brake with Variable-Speed Pump. Symposium on Fluid Power and Motion Control. Chicago, Illinois, USA.

[6] LINJAMA, M., LAAMANEN, A., VILENIUS, M., 2003. Is it time for digital hydraulics? The Eighth Scandinavian International Conference on Fluid Power, May 7-9, Tampere, Finland, pp. 347-366.

[7] BELAN, H, B., LOCATELI, C. C., ENDLER, L., PIERI, E. R. D. \& DE NEGRI, V.J., 2014. Aumento da eficiência energética em sistemas hidráulicos utilizando hidráulica digital. $X X$ Congresso Brasileiro de Automática, Belo Horizonte, Brazil, 20 - 24 Sept.

[8] BELAN, H. B., LOCATELI, C. C., LANTTO, B., KRUS. P. \& DE NEGRI, V. J., 2015. Digital Secondary Control Architecture for Aircraft Application. The Seventh Workshop on Digital Fluid Power, February 26-27, Linz, Austria.

[9] LINJAMA, M., VILENIUS, M., 2008. DIGITAL HYDRAULICS - Towards Perfect Valve Technology. Technology. Digitalna Hidravlika, Ventil 14. 2. pp. 138-148.

[10] SCHEIDL, R.; KOGLER, H.; WINKLER, B., 2013. Hydraulic Switching Control - objectives, concepts, challenges and potential applications. Magazine of Hydraulics, Pneumatics, Tribology, Ecology, Sensorics, Mechatronics, n. 1, ISSN: 1453 - 7303.

[11] SELL, N. P., JOHNSTON, D. N., A. R. PLUMMER. \& KUDZMA, S., 2013. Control of a fast switching valve for digital hydraulics. The $13^{\text {th }}$ Scandinavian International Conference on Fluid Power, SICFP2013, June 3-5, Linköping, Sweden.

[12] BROWN, F. T., 1987. Switched reactance hydraulics: a new way to control fluid power. Proc. National Conference on Fluid Power. Chicago, USA, pp. 25-34.

[13] BROWN, F. T. TENTARELLI, S. C., RAMACHANDRAN, S. A., 1988. A hydraulic rotary switched-inertance servo-transformer, Transactions of ASME: Journal of Dynamic Systems, Measurement, and Control. Vol. 110, pp.144-150. 
[14] DE NEGRI, V.J., NOSTRANI, M.P., WANG P., JOHNSTON D.N., PLUMMER, A., 2015. Modelling and analysis of hydraulic step-down switching converters, International Journal of Fluid Power. Vol 16, No. 2, pp. 111-121.

[15] NOSTRANI, M. P., GALLONI, A., RADUENZ, H., DE NEGRI, V.J., 2016. Theoretical and experimental analysis of a hydraulic step-down switching converter for position and speed control. The Eighth Workshop on Digital Fluid Power. Tampere. Proceedings of DFP2016, 2016. pp. 1-19.

[16] SZPAK, R. Análise Teórico-Experimental das Pressões em Posicionadores Hidráulicos. 2008. Dissertação (Mestrado em Engenharia Mecânica) Programa de Pós-graduação em Engenharia Mecânica, Universidade Federal de Santa Catarina, Florianópolis.

[17] WELLSTEAD, P. E., 2000. Introduction to Physical System Modelling. London: Ed. Academic Press Ltd., 244 p.

[18] FOX, R. W., MCDONALD, A. T., Pritchard, P. J., 2011. Introduction to Fluid Mechanics, $8^{\text {th }}$ ed. Hoboken, NJ: Wily.

[19] GONZALEZ, F. E., DE NEGRI, V. J., SOARES, J. M. C., 2012. Analysis and Emulation of Actuating Forces on Wind Turbine Pitch Drives. 8th International Fluid Power Conference - 8. IFK, Aachen-Germany.

[20] DE NEGRI, V. J., RAMOS FILHO, J. R. B., SOUZA, A. D. C. de., 2008. A Design Method for Hydraulic Positioning Systems. 51th National Conference on Fluid Power (NCFP), Las Vegas, USA.

[21] MURARO, I., TEIXEIRA, P. L., DE NEGRI, V. J., 2013. Effect of proportional valves and cylinders on the behavior of hydraulic positioning systems. In: ASME/BATH Symposium on Fluid Power \& Motion Control, Sarasota, FL. pp.1 - 9.

[22] GONZALEZ, F. E., 2012. Estudo das Forças Atuantes em Mecanismos de Regulação de Ângulo de Passo e Desenvolvimento de um Sistema Emulador de Cargas. Dissertação (Mestrado em Engenharia Mecânica)-Universidade Federal de Santa Catarina, Florianópolis,

[23] NOSTRANI, M. P., 2015. Estudo teóricoexperimental de um posicionador utilizando hidráulica digital de chaveamento rápido: estudo de caso em bancada de ensaios para turbinas eólicas. Dissertação (Programa de Pós Graduação em Engenharia Mecânica), Universidade Federal de Santa Catarina, Florianópolis.

[24] KRUS, P., WEDDFELT, K., PALMBERG, J.-O., 1994. Fast pipeline models for simulation of hydraulic systems. Journal of Dynamic Systems,
Measurement, and Control. Vol.116. pp. 132-136. March.

[25] JOHNSTON, D.N., 2006. Efficient Methods for Numerical Modeling of Laminar Friction in Fluid Lines. Journal of Dynamic Systems, Measurement, and Control. December, Vol. 128. pp. 829-834. DOI: 10.1115/1.2361320,

[26] JOHNSTON, D.N., 2012. The transmission line method for modelling laminar flow of liquid in pipelines. Proc. IMechE Part I: Journal of Systems and Control Engineering, Vol. 226. pp. 586-597. DOI: $10.1177 / 0959651811430035$. 